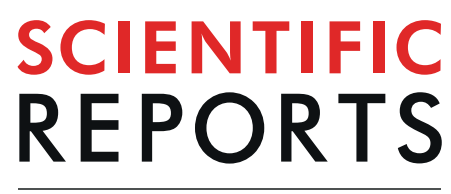

natureresearch

Check for updates

\title{
OPEN Clinical and Genetic Characteristics of 18 Patients from 13 Japanese Families with CRX-associated retinal disorder: Identification of Genotype-phenotype Association
}

Yu Fujinami-Yokokawa ${ }^{1,2,3,57}$, Kaoru Fujinami ${ }^{1,4,5,6,57 凶}$, Kazuki Kuniyoshi ${ }^{7}$, Takaaki Hayashi ${ }^{8}$, Shinji Ueno ${ }^{9}$, Atsushi Mizota ${ }^{10}$, Kei Shinoda ${ }^{10,11}$, Gavin Arno ${ }^{1,5,6,12}$, Nikolas Pontikos $\mathbb{1}^{1,5,6}$, Lizhu Yang ${ }^{1,4}$, Xiao Liu ${ }^{1,4,13}$, Hiroyuki Sakuramoto ${ }^{7}$, Satoshi Katagiri ${ }^{8}{ }^{8}$, Kei Mizobuchi ${ }^{8}$, Taro Kominami ${ }^{9}$, Hiroko Terasaki ${ }^{9}$, Natsuko Nakamura ${ }^{1,14}$, Shuhei Kameya ${ }^{15}$, Kazutoshi Yoshitake ${ }^{16}$, Yozo Miyake ${ }^{1,17,18}$, Toshihide Kurihara $\mathbb{1}^{4}$, Kazuo Tsubota ${ }^{4}{ }^{4}$, Hiroaki Miyata ${ }^{2,19}$, Takeshi Iwata $\mathbb{1}^{16}$, Kazushige Tsunoda ${ }^{1}$ \& Japan Eye Genetics Consortium ${ }^{1,16 *}$

Inherited retinal disorder (IRD) is a leading cause of blindness, and CRX is one of a number of genes reported to harbour autosomal dominant $(A D)$ and recessive (AR) causative variants. Eighteen patients from 13 families with CRX-associated retinal disorder (CRX-RD) were identified from 730 Japanese families with IRD. Ophthalmological examinations and phenotype subgroup classification were performed. The median age of onset/latest examination was 45.0/62.5 years (range, 15-77/25-94). The median visual acuity in the right/left eye was $0.52 / 0.40$ (range, $-0.08-2.00 /-0.18-1.70$ ) logarithm of the minimum angle of resolution (LogMAR) units. There was one family with macular dystrophy, nine with cone-rod dystrophy (CORD), and three with retinitis pigmentosa. In silico analysis of CRX variants was conducted for genotype subgroup classification based on inheritance and the presence of truncating variants. Eight pathogenic $C R X$ variants were identified, including three novel heterozygous variants (p.R43H, p.P145Lfs*42, and p.P197Afs*22). A trend of a genotype-phenotype association was revealed between the phenotype and genotype subgroups. A considerably high proportion of $C R X-R D$

${ }^{1}$ Laboratory of Visual Physiology, Division of Vision Research, National Institute of Sensory Organs, National Hospital Organization Tokyo Medical Center, Tokyo, 152-8902, Japan. ${ }^{2}$ Department of Health Policy and Management, Keio University School of Medicine, Tokyo, Japan. ${ }^{3}$ Division of Public Health, Yokokawa Clinic, Suita, 564-0083, Japan. ${ }^{4}$ Department of Ophthalmology, Keio University School of Medicine, Tokyo, 160-8582, Japan. ${ }^{5} \mathrm{UCL}$ Institute of Ophthalmology, London, EC1V 9EL, UK. ${ }^{6}$ Moorfields Eye Hospital, London, EC1V 2PD, UK. ${ }^{7}$ Department of Ophthalmology, Kindai University Faculty of Medicine, Osaka-Sayama, 589-8511, Japan. ${ }^{8}$ Department of Ophthalmology, The Jikei University School of Medicine, Tokyo, 105-8461, Japan. ${ }^{9}$ Department of Ophthalmology, Nagoya University Graduate School of Medicine, Nagoya, 466-8550, Japan. ${ }^{10}$ Department of Ophthalmology, Teikyo University, Tokyo, 173-8605, Japan. ${ }^{11}$ Department of Ophthalmology, Saitama Medical University, Saitama, 3500495, Japan. ${ }^{12}$ North East Thames Regional Genetics Service, UCL Great Ormond Street Institute of Child Health, Great Ormond Street NHS Foundation Trust, London WC1N 1EH, London, UK. ${ }^{13}$ Southwest Hospital/Southwest Eye Hospital, Third Military Medical University, Chongqing, 400030, China. ${ }^{14}$ Department of Ophthalmology, The University of Tokyo, Tokyo, 113-8654, Japan. ${ }^{15}$ Department of Ophthalmology, Nippon Medical School Chiba Hokusoh Hospital, Inzai, 270-1694, Japan. ${ }^{16}$ Division of Molecular and Cellular Biology, National Institute of Sensory Organs, National Hospital Organization Tokyo Medical Center, Tokyo, 152-8902, Japan. ${ }^{17}$ Aichi Medical University, Nagakute, 480-1195, Japan. ${ }^{18}$ Kobe Eye Center, Next Vision, Kobe, 650-0047, Japan. ${ }^{19}$ Department of Healthcare Quality Assessment, University of Tokyo, Tokyo, 113-8655, Japan. ${ }^{57}$ These authors contributed equally: Yu FujinamiYokokawa and Kaoru Fujinami. *A list of authors and their affiliations appears at the end of the paper. ${ }^{凶}$-mail: $k$. fujinami@ucl.ac.uk 
in ADCORD was determined in the Japanese cohort (39.1\%), often showing the mild phenotype (CORD) with late-onset disease (sixth decade). Frequently found heterozygous missense variants located within the homeodomain underlie this mild phenotype. This large cohort study delineates the disease spectrum of $C R X-R D$ in the Japanese population.

Inherited retinal disorder (IRD) is one of the major causes of blindness in developed countries in both adults and children ${ }^{1}$ and includes retinitis pigmentosa (RP), cone/cone-rod dystrophy (CORD), Stargardt disease (STGD), macular dystrophy (MD), Leber congenital amaurosis (LCA) and others. Different inheritance patterns are found in IRD: autosomal dominant (AD), autosomal recessive (AR), X-linked, and mitochondrial inheritance ${ }^{2-9}$. For instance, different inheritance patterns result in different phenotypes (GUCY2D, BEST1, PROM1) in some genes, while other genes are associated with different phenotypes with similar inheritance patterns $(A B C A 4, P R P H 2$, $R P G R, K C N V 2$, GNGA3, CNGB3 $)^{8-17}$.

$C R X$, denoted as a cone-rod homeobox-containing gene (OMIM: 602225) with high homology to the OTX family of homeobox genes, is located on 19q13.33 and contains four exons encoding a 299-amino acid homeodomain transcription factor crucial for the development and survival of photoreceptors ${ }^{18}$. Animal experiments have proven that $C R X$ is predominantly expressed in vertebrate photoreceptor cells of the retina and pinealocytes of the pineal gland ${ }^{19,20}$, playing a significant role in the differentiation and maintenance of photoreceptor cells by synergistic interactions with other transcription factors, such as neural retina-specific leucine zipper protein

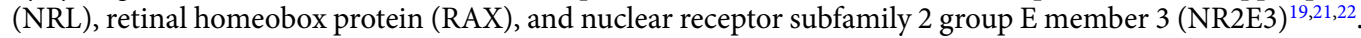

A locus and gene for ADCORD (CORD2) was first mapped and identified as CRX in $1994^{18,23}$. Since then, over 90 variants in the $C R X$ gene have been associated with a wide range of different phenotypes of IRDs, including CORD, LCA, MD, and RP (The Human Gene Mutation Database; http://www.hgmd.cf.ac.uk/ac/index.php; accessed on 1 August 2018) ${ }^{24-35}$. The predominant mode of inheritance in reported families is AD, and in a few patients, including Japanese with RP or LCA caused by homozygous CRX variants was reported ${ }^{29,36}$.

Studies of $C R X$-associated retinal disorder (CRX-RD) have often been separately conducted for each phenotype, such as CORD or RP/LCA ${ }^{16,24,26,27,32,36}$; thus, it has been hard to comprehensively understand the disorder in consideration of different phenotypes and different modes of inheritance. To solve such a problem, large cohort studies with standardized clinical and genetic investigations for IRDs are required.

The purpose of this study was to characterize the clinical and molecular genetic features of CRX-RD in a nationwide large cohort of Japanese subjects diagnosed with IRD.

\section{Results}

Participants. Eighteen affected subjects from 13 Japanese families with a clinical diagnosis of IRD and harbouring $C R X$ variants were identified in this study. The detailed clinical information is provided in Table 1 , and the pedigrees of the 13 families are demonstrated in Fig. 1.

There were seven families with clear AD family history (7/13, 53.8\%; Families 1, 2, 4, 5, 6, 7, 13), one family with a family history consistent with AR inheritance with affected siblings born to unaffected parents $(1 / 13,7.7 \%$; Family 9), and 3 sporadic cases $(3 / 13,23.1 \%$; Families $8,10,11)$. Two families lacked clear family data: one with unknown parental affected status (Family 3 ) and the other with the presence of an affected deceased paternal great grandfather (Family 12). Consanguineous marriage was not clearly reported in all families.

There were eight affected females $(8 / 18,44.4 \%)$ and ten affected males $(10 / 18,55.6 \%)$. The median age at the latest examination of 18 affected subjects was 62.5 years (range, 25-94).

Onset and visual acuity. The median age of onset of 13 affected subjects with available records was 45.0 years (range, 15-77). One subject had a childhood onset at 15 years of age (1/13, 7.6\%; Patient 16). Late onset of 45 years of age or later was reported in seven subjects $(7 / 13,53.8 \%$; Patients $3,8,9,10,12,15,17)$.

The median best-corrected decimal visual acuity (VA) converted to the logarithm of the minimum angle of resolution (LogMAR) in the right and left eye of 18 affected subjects with available records was 0.52 (range, $-0.08-2.00)$ and $0.40(-0.18-1.70)$, respectively. Eight out of 18 subjects had relatively favourable VA $(8 / 18$, $44.4 \%$, Patients $1,2,3,7,11,12,15,17 ; 0.22$ or better LogMAR units in the better eye), eight had intermediate VA $(8 / 18,44.4 \%$, Patients $5,6,9,10,13,14,16,18$; between 0.22 and 1.0 LogMAR units in the better eye). There were eight eyes from six patients with poor VA (8/36, 22.2\%, Patient 1-right, 3-right, 4-both, 5-left, 8-both, 14-left; 1.0 or worse LogMAR units).

Retinal imaging and morphological findings. Fundus photographs were obtained in 18 affected subjects, and fundus autofluorescence (FAF) images were available in 13 affected subjects (Patients 1-3, 7, 8, 10-13, 15-18). Representative images are presented in Fig. 2. The detailed findings are described in Supplemental Table 1 .

Marked macular atrophy was demonstrated in nine affected subjects $(9 / 18,50.0 \%$; Patients 1, 3-6, 8, 15, 17, $18)$, and slight atrophic changes at the macula were found in three $(3 / 18,16.7 \%$; Patients $7,11,12)$. Marked peripheral atrophy was observed in four subjects $(4 / 18,22.2 \%$; Patients $5,13,14,16)$. Marked atrophic changes along the arcade were noted in eight subjects $(8 / 18,44.4 \%$; Patients $1,2,4,5,8,10,14,16)$, and slight atrophic changes along the arcade were noted in two subjects $(2 / 18,11.1 \%$; Patients 9,13$)$. Three of these ten subjects with atrophy along the arcade had isolated atrophy without macular or peripheral atrophy (Patients 2, 9, 10). One subject presented with atrophic changes affecting the entire retina, including the macula, mid-periphery, and periphery (1/18, 5.6\%; Patient 5).

Retinal atrophy at the macula was more evident on FAF images in eight subjects $(8 / 13,61.5 \%$; Patients $1,3,8$, $11,12,15,17,18)$. A ring of high density AF was observed in 11 subjects to various degrees; eight with a ring that 


\begin{tabular}{|c|c|c|c|c|c|c|c|c|c|c|c|c|c|c|}
\hline \multirow[b]{2}{*}{$\begin{array}{l}\text { Family } \\
\text { No. }\end{array}$} & \multirow[b]{2}{*}{$\begin{array}{l}\text { Patient } \\
\text { No. }\end{array}$} & \multirow{2}{*}{$\begin{array}{l}\text { JEGC } \\
\text { consortium } \\
\text { ID }\end{array}$} & \multirow{2}{*}{$\begin{array}{l}\text { Inheritance } \\
\text { based on } \\
\text { family history }\end{array}$} & \multirow[b]{2}{*}{ Sex } & \multirow[b]{2}{*}{$\begin{array}{l}\text { Age (at latest } \\
\text { examination) }\end{array}$} & \multirow[b]{2}{*}{ Onset } & \multirow[b]{2}{*}{$\begin{array}{l}\text { Chief } \\
\text { complaint }\end{array}$} & \multicolumn{2}{|c|}{ Refractive errors } & \multicolumn{2}{|c|}{$\begin{array}{l}\text { BCVA } \\
\text { (LogMAR unit) }\end{array}$} & \multirow[b]{2}{*}{$\begin{array}{l}\text { Phenotype } \\
\text { subgroup }\end{array}$} & \multirow{2}{*}{$\begin{array}{l}\text { Molecularly } \\
\text { raised } \\
\text { inheritance }\end{array}$} & \multirow[b]{2}{*}{$\begin{array}{l}\text { CRX } \\
\text { variants }\end{array}$} \\
\hline & & & & & & & & \begin{tabular}{|l|} 
RE \\
(dioptre)
\end{tabular} & \begin{tabular}{|l|} 
LE \\
(dioptre)
\end{tabular} & RE & LE & & & \\
\hline 1 & $\begin{array}{l}\text { Patient } 1 \\
\text { (1-III:1) }\end{array}$ & $\begin{array}{l}\text { TMC-001- } \\
001\end{array}$ & $\mathrm{AD}$ & M & 44 & 35 & $\begin{array}{l}\text { Reduced } \\
\text { visual acuity }\end{array}$ & -5.5 & -5.0 & 1.1 & 0.1 & CORD & $\mathrm{AD}$ & $\begin{array}{l}\text { c. } 118 \mathrm{C}>\mathrm{T}, \\
\text { p.R40W }\end{array}$ \\
\hline 1 & $\begin{array}{l}\text { Patient } 2 \\
\text { (1-II:3) }\end{array}$ & $\begin{array}{l}\text { TMC-001- } \\
002\end{array}$ & $\mathrm{AD}$ & $\mathrm{F}$ & 72 & NA & Photophobia & -0.5 & -0.5 & 0 & 0 & CORD & $\mathrm{AD}$ & $\begin{array}{l}\text { c. } 118 \mathrm{C}>\mathrm{T}, \\
\text { p.R40W }\end{array}$ \\
\hline 2 & \begin{tabular}{|l|} 
Patient 3 \\
(2-II:1)
\end{tabular} & JU-001-001 & $\mathrm{AD}$ & $\mathrm{F}$ & 71 & 56 & $\begin{array}{l}\text { Reduced } \\
\text { visual acuity }\end{array}$ & 0.5 & -1.5 & 1.0 & 0.2 & CORD & $\mathrm{AD}$ & $\begin{array}{l}\text { c. } 118 \mathrm{C}>\mathrm{T}, \\
\text { p.R40W }\end{array}$ \\
\hline 2 & \begin{tabular}{|l} 
Patient 4 \\
(2-I:2)
\end{tabular} & JU-001-002 & $\mathrm{AD}$ & $\mathrm{F}$ & 94 & 30 & $\begin{array}{l}\text { Reduced } \\
\text { visual acuity }\end{array}$ & 0.0 & 0.0 & 2.0 & $\mathrm{CF}$ & CORD & $\mathrm{AD}$ & $\begin{array}{l}\text { c.118C }>\text { T, } \\
\text { p.R40W }\end{array}$ \\
\hline 3 & \begin{tabular}{|l|} 
Patient 5 \\
(3-II:2)
\end{tabular} & $\begin{array}{l}\text { KDU-001- } \\
001\end{array}$ & Unknown & $\mathrm{F}$ & 76 & NA & $\begin{array}{l}\text { Reduced } \\
\text { visual acuity }\end{array}$ & -3.5 & NA & 0.4 & 1.7 & CORD & $\mathrm{AD}$ & $\begin{array}{l}\text { c.118C }>\text { T, } \\
\text { p.R40W }\end{array}$ \\
\hline 4 & \begin{tabular}{|l} 
Patient 6 \\
(4-III:2)
\end{tabular} & NU-001-001 & $\mathrm{AD}$ & $\mathrm{M}$ & 32 & NA & Photophobia & -0.5 & -0.5 & 0.52 & 0.52 & CORD & $\mathrm{AD}$ & $\begin{array}{l}\text { c. } 121 \mathrm{C}>\mathrm{T}, \\
\text { p.R41W }\end{array}$ \\
\hline 5 & \begin{tabular}{|l} 
Patient 7 \\
(5-II:1)
\end{tabular} & JU-002-001 & $\mathrm{AD}$ & M & 63 & NA & $\begin{array}{l}\text { Reduced } \\
\text { visual acuity }\end{array}$ & +1.0 & +1.5 & 0.15 & 0.4 & CORD & $\mathrm{AD}$ & $\begin{array}{l}\text { c.121C>T, } \\
\text { p.R41W }\end{array}$ \\
\hline 5 & \begin{tabular}{|l} 
Patient 8 \\
(5-I:1)
\end{tabular} & JU-002-002 & $\mathrm{AD}$ & M & 88 & 60 & $\begin{array}{l}\text { Night } \\
\text { blindness }\end{array}$ & 0 & -0.5 & 1.15 & 1.22 & CORD & $\mathrm{AD}$ & $\begin{array}{l}\text { c. } 121 \mathrm{C}>\mathrm{T}, \\
\text { p.R41W }\end{array}$ \\
\hline 6 & \begin{tabular}{|l} 
Patient 9 \\
(6-III:1)
\end{tabular} & $\begin{array}{l}\text { KDU-002- } \\
001\end{array}$ & $\mathrm{AD}$ & $\mathrm{F}$ & 80 & 75 & $\begin{array}{l}\text { Reduced } \\
\text { visual acuity }\end{array}$ & 0.0 & 0.0 & 0.52 & 0.82 & CORD & $\mathrm{AD}$ & $\begin{array}{l}\text { c.127C }>\text { T, } \\
\text { p.R43C }\end{array}$ \\
\hline 6 & $\begin{array}{l}\text { Patient } 10 \\
\text { (6-III:2) }\end{array}$ & $\begin{array}{l}\text { KDU-002- } \\
002\end{array}$ & $\mathrm{AD}$ & $\mathrm{M}$ & 83 & 77 & $\begin{array}{l}\text { Reduced } \\
\text { visual acuity }\end{array}$ & +2.0 & +2.0 & 0.7 & 0.7 & CORD & $\mathrm{AD}$ & $\begin{array}{l}\text { c. } 127 \mathrm{C}>\mathrm{T}, \\
\text { p.R43C }\end{array}$ \\
\hline 7 & $\begin{array}{l}\text { Patient } 11 \\
\text { (7-III:3) }\end{array}$ & $\begin{array}{l}\text { TMC-002- } \\
001\end{array}$ & $\mathrm{AD}$ & M & 35 & 31 & $\begin{array}{l}\text { Central } \\
\text { visual field } \\
\text { loss }\end{array}$ & NA & NA & 0.22 & 0.4 & $\mathrm{MD}$ & $\mathrm{AD}$ & $\begin{array}{l}\text { c. } 128 G>A, \\
\text { p.R43H }\end{array}$ \\
\hline 7 & $\begin{array}{l}\text { Patient } 12 \\
\text { (7-II:2) }\end{array}$ & $\begin{array}{l}\text { TMC-002- } \\
002\end{array}$ & $\mathrm{AD}$ & M & 63 & 62 & $\begin{array}{l}\text { No } \\
\text { symptoms }\end{array}$ & NA & NA & -0.08 & -0.08 & MD & $\mathrm{AD}$ & $\begin{array}{l}\text { c. } 128 G>A, \\
\text { p. } R 43 H\end{array}$ \\
\hline 8 & $\begin{array}{l}\text { Patient } 13 \\
(8 \text {-II:2) }\end{array}$ & $\begin{array}{l}\text { TMC-003- } \\
001\end{array}$ & Sporadic & $\mathrm{F}$ & 41 & 37 & $\begin{array}{l}\text { Reduced } \\
\text { visual acuity }\end{array}$ & +1.5 & -0.5 & 0.7 & 0.4 & $\mathrm{RP}$ & $\mathrm{AR}$ & $\begin{array}{l}\text { c. } 193 \mathrm{G}>\mathrm{C}, \\
\text { p.D65H/ } \\
\text { c.193G }>C, \\
\text { p.D65H }\end{array}$ \\
\hline 9 & $\begin{array}{l}\text { Patient } 14 \\
\text { (9-II:4) }\end{array}$ & $\begin{array}{l}\text { KDU-003- } \\
001\end{array}$ & $\mathrm{AR}$ & M & 50 & NA & NA & -2.0 & NA & 0.82 & LP & $\mathrm{RP}$ & $\mathrm{AR}$ & $\begin{array}{l}\text { c. } 193 \mathrm{G}>\mathrm{C}, \\
\text { p.D65H/ } \\
\text { c. } 193 \mathrm{G}>\mathrm{C}, \\
\text { p.D65H }\end{array}$ \\
\hline 10 & $\begin{array}{l}\text { Patient } 15 \\
\text { (10-II:3) }\end{array}$ & JU-003-001 & Sporadic & M & 55 & 45 & $\begin{array}{l}\text { Reduced } \\
\text { visual acuity }\end{array}$ & -3.5 & -3.5 & 0.22 & -0.18 & CORD & $\mathrm{AD}$ & $\begin{array}{l}\text { c. } 268 \mathrm{C}>\mathrm{T} \text {, } \\
\text { p.R90W }\end{array}$ \\
\hline 11 & $\begin{array}{l}\text { Patient 16 } \\
\text { (11-III:3) }\end{array}$ & $\begin{array}{l}\text { KDU-004- } \\
001\end{array}$ & Sporadic & $\mathrm{F}$ & 25 & 15 & $\begin{array}{l}\text { Night } \\
\text { blindness }\end{array}$ & -3.5 & -5.0 & 0.52 & 0.7 & $\mathrm{RP}$ & $\begin{array}{l}\mathrm{AD}(\mathrm{de} \\
\text { novo) }\end{array}$ & $\begin{array}{l}\text { c.430delC, } \\
\text { p.P145Lfs } * 42\end{array}$ \\
\hline 12 & $\begin{array}{l}\text { Patient } 17 \\
(12 \text {-IV:1) }\end{array}$ & TU-001-001 & Unknown & M & 51 & 45 & $\begin{array}{l}\text { Reduced } \\
\text { visual acuity }\end{array}$ & -2.5 & -2.5 & 0 & -0.08 & CORD & $\mathrm{AD}$ & $\begin{array}{l}\text { c.587delC, } \\
\text { p.P197Afs } * 22\end{array}$ \\
\hline 13 & $\begin{array}{l}\text { Patient } 18 \\
\text { (13-III:1) }\end{array}$ & $\begin{array}{l}\text { TMC-004- } \\
001\end{array}$ & $\mathrm{AD}$ & $\mathrm{F}$ & 62 & 30 & $\begin{array}{l}\text { Reduced } \\
\text { visual acuity }\end{array}$ & -1.0 & -1.0 & 0.82 & 0.82 & CORD & $\mathrm{AD}$ & \begin{tabular}{|l|} 
c.587delC, \\
p.P197Afs $* 22$
\end{tabular} \\
\hline
\end{tabular}

Table 1. Demographics and detected variants in 18 Japanese patients from 13 families with CRX-associated retinal disorder (CRX-RD). $\mathrm{AD}=$ autosomal dominant; $\mathrm{AR}=$ autosomal recessive; $\mathrm{CORD}=$ cone-rod dystrophy; $\mathrm{F}=$ female; $\mathrm{CF}=$ counting finger $\mathrm{LCA}=$ Leber congenital amaurosis; $\mathrm{LE}=$ left eye; LogMAR $\mathrm{BCVA}=$ best-corrected Snellen visual acuity converted to the logarithm of the minimum angle of resolution visual acuity; $\mathrm{LP}=$ light perception; $\mathrm{M}=$ male; $\mathrm{MD}=$ macular dystrophy; No.=number; $\mathrm{NA}=$ not available; $\mathrm{RE}=$ right eye; $\mathrm{RP}=$ retinitis pigmentosa. All affected and unaffected subjects are originally from Japan and any mixture with other ethnicity was not reported. Age was defined as the age when the latest examination was performed. The age of onset was defined as either the age at which visual loss was first noted by the patient or when an abnormal retinal finding was first detected. Phenotype subgroup was defined based on clinical manifestations such as onset of disease, natural course, lesioned part on retinal imaging, and pattern of retinal dysfunction: LCA (including early-onset RP), a severe retinal dystrophy with early onset ( $<10$ years) and extinguished retinal function; RP (including rod-cone dystrophy), a progressive retinal dystrophy often initially presenting peripheral atrophy with generalized rod dysfunction greater than cone dysfunction; CORD, a progressive retinal dystrophy often initially presenting macular atrophy with generalized cone dysfunction greater than rod dysfunction; $\mathrm{MD}$, a progressive retinal dystrophy presenting macular atrophy with confined macular dysfunction despite no abnormalities in generalized cone and rod function. Syndromic findings of central nervous system abnormalities (described as multiple sclerosis-like changes) were reported in Patient 8.

surrounded the macular changes $(8 / 11,72.7 \%$, Patients $1,3,8,11,12,15,17,18)$ and three with a ring that surrounded the mid-peripheral changes $(3 / 11,27.2 \%$; Patients $2,7,13)$. Foveal appearance was relatively preserved in nine subjects $(9 / 13,69.2 \%$; Patients $1-3,7,10-12,16,17)$.

Spectral-domain optical coherence tomography (SD-OCT) was obtained in 18 affected subjects, and representative images are presented in Fig. 3. Marked outer retinal disruption was demonstrated at the macula in eight 


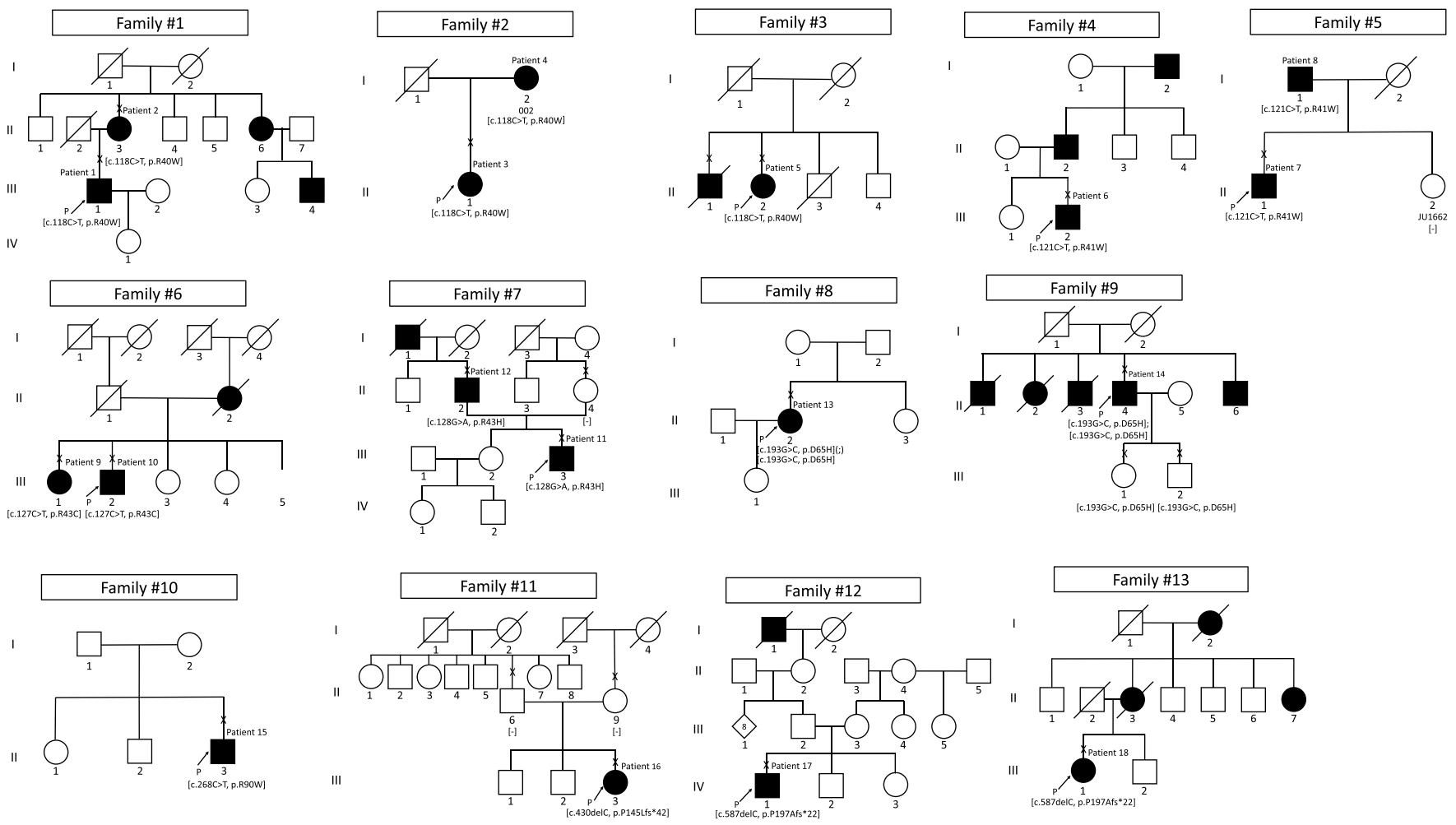

Figure 1. Pedigrees of 13 Japanese families with inherited retinal disorder harbouring $C R X$ variants. The solid squares and circles (men and women, respectively) represent the affected subjects, and the white icons represent the unaffected family members. The slash symbol shows deceased individuals. The generation number is noted on the left. The proband is marked by an arrow, and the clinically investigated individuals are indicated by a cross.

subjects $(8 / 18,44.4 \%$; Patients $1,3,4,5,6,8,15,18)$. Outer retinal disruption in the peri-macula was observed in 12 subjects $(12 / 18,66.7 \%$; Patients $1-6,8,13-15,17,18)$, and slight outer retinal disruption in the peri-macula was found in four subjects $(4 / 18,22.2 \%$; Patients 10-12,16). Intraretinal micro-cystic changes and marked intraretinal fluid were noted in the right and left eyes, respectively, of Patient 13 (1/18, 5.6\%).

Marked preservation of the photoreceptor ellipsoid zone (EZ) at the fovea was identified in eight subjects $(8 / 18,44.4 \%$; Patients $2,5,7,10-14)$, and slightly preserved EZ at the fovea was seen in three subjects $(3 / 18$, 16.7\%; Patients 9, 16, 17). Preserved foveal structure surrounded by parafoveal atrophy (i.e., bull's eye pattern) was observed in six subjects (6/18, 33.3\%; Patient 1-left, 2-both, 10-both, 11-both, 12-both, 17-both).

Visual fields and electrophysiological findings. The detailed findings of visual fields and electrophysiological findings are presented in Supplemental Table 2. Visual field testing was performed in 14 affected subjects (Patients 1, 3, 5, 7, 9-18). Central scotoma and paracentral scotoma were detected in eight subjects $(8 / 14,57.1 \%$; Patients $1,3,5,7,9,10,15,18)$. Paracentral scotoma without central scotoma was observed in five subjects $(5 / 14$, 35.7\%; Patients 11, 13, 14, 16, 17). Peripheral visual field defects were found in 5 patients $(5 / 14,35.7 \%$; Patients 9 , $10,13,14,16)$, two of whom also had central and paracentral scotoma (Patients 9, 10) and three had paracentral scotoma (Patients 13, 14, 16).

Full-field electroretinograms (ffERGs) were recorded in 16 affected subjects (Patients 1-3, 5-14, 16-18). Mildly decreased generalized light-adapted (LA) responses were demonstrated in six subjects $(6 / 16,37.5 \%$; Patients $1,3,6,7,17,18$ ), five of whom had mildly decreased generalized dark-adapted (DA) responses (Patients $1,3,6,7,17)$. Severely decreased generalized LA and DA responses were detected in four subjects $(4 / 16,25.0 \%$; Patients $8,13,14,16)$, and moderately decreased generalized DA responses were found in one subject with unavailable LA responses $(1 / 16,6.3 \%$; Patient 2$)$. In two subjects, both generalized DA and LA responses were within normal limits $(2 / 16,12.5 \%$; Patients 11,12$)$. A lower b to a ratio in DA bright flash responses (less than 0.9$)$ was identified in seven subjects (7/16, 43.8\%; Patients 2, 5, 6, 10-12, 17).

Multifocal ERGs (mfERGs) were recorded in four subjects (Patients 1, 9, 13, 18). Reductions in central responses were observed in three subjects (Patients 9, 13, 18), and a gross reduction in stimulus fields was found in one subject (Patient 1).

Phenotype subgroups. Phenotype subgroup classification was performed in all 18 affected subjects. There were 13 subjects with CORD (13/18, 72.2\%; Patients 1-10, 15, 17, 18), three with RP (3/18, 16.7\%; Patients 13, 14, 


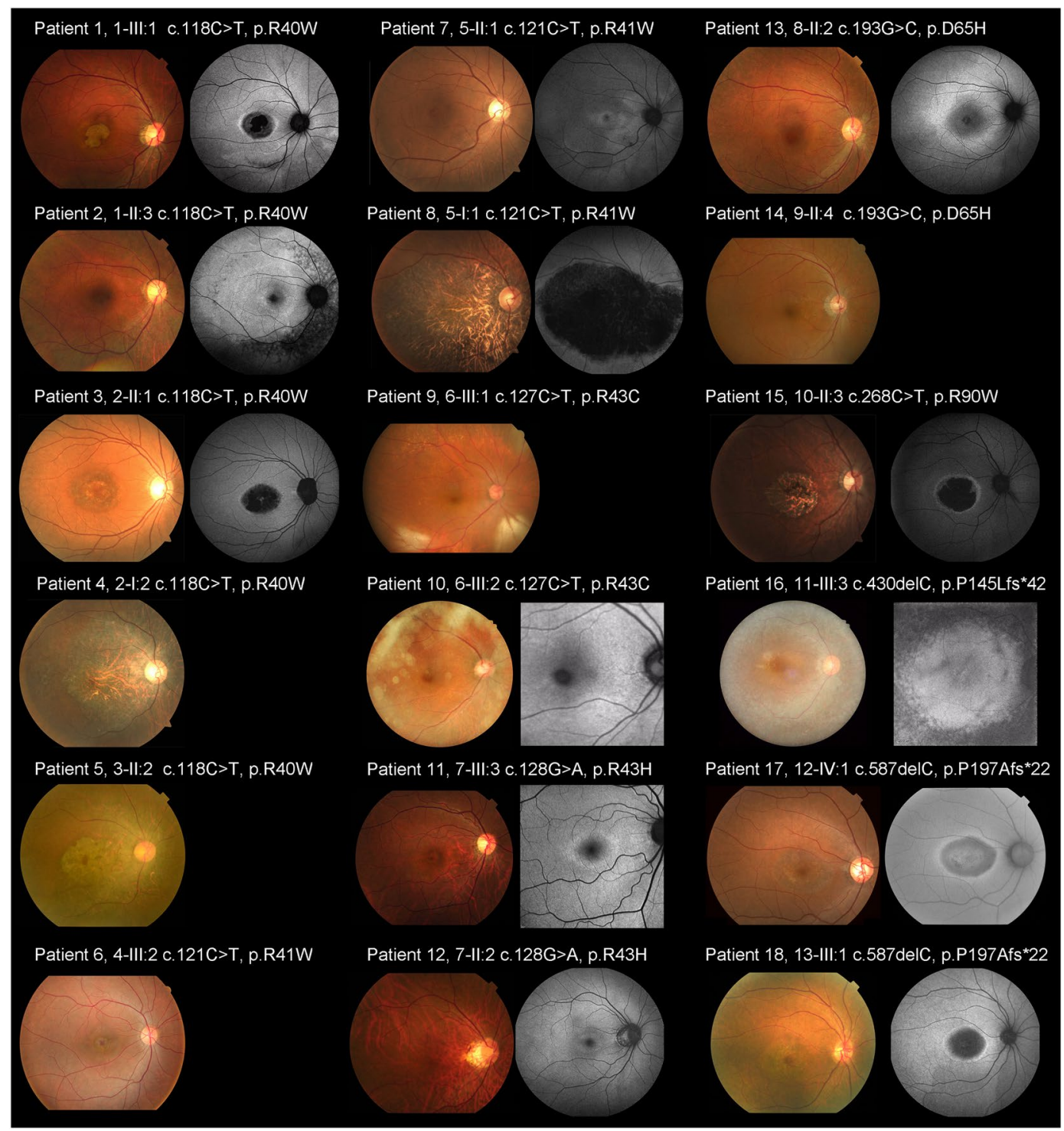

Figure 2. Fundus photographs and fundus autofluorescence images from 18 patients with $C R X$-associated retinal disorder $(C R X-\mathrm{RD})$. Fundus photographs and fundus autofluorescence (FAF) images demonstrate macular atrophy in nine subjects (Patients $1,3-6,8,15,17,18)$ and slight atrophic changes at the macula in three subjects (Patients 7, 11, 12). Peripheral atrophy is observed in four subjects (Patients 5, 13, 14, 16; detected by fundoscopy in Patients 5 and 14). Atrophic changes affecting the entire retina, including the macula, midperiphery, and periphery are found in Patient 5. Macular atrophy is more evident on FAF images in eight subjects (Patients $1,3,8,11,12,15,17,18$ ). A ring of high density AF is observed in 11 subjects to various degrees (Patients 1, 2, 3, 7, 8, 11-13, 15, 17, 18). Foveal appearance is relatively preserved in nine subjects (Patients 1-3, 7, 10-12, 16, 17).

$16)$, and two with $\operatorname{MD}(2 / 18,11.1 \%$; Patients 11,12$)$. Intrafamilial differences in phenotypic subgroups among the affected subjects were not observed in all five families with multiple affected subjects (Families 1, 2, 5, 6, 7).

The mean age of onset of the two subjects with MD, 13 subjects with CORD, and three subjects with RP was 46.5 (range, 31-62), 50.3 (range, 30-77), and 26.0 (range, 15-37), respectively. The mean VA in the right/ left eye of those with MD, CORD, and RP was $0.07 / 0.16$ (range, $-0.08-0.22 /-0.08-0.4$ ), 0.52/0.46 (range, 0.02.00/-0.18-1.7), and 0.68/0.55 (range, 0.52-0.82/0.4-light perception) LogMAR units, respectively.

$C R X$ variants. Variant data of 18 affected and 6 unaffected individuals from 13 families with CRX-RD are summarized in Supplemental Table 3. Seven heterozygous variants and one homozygous variant were identified by whole exome sequencing with target analysis of retinal disease-associated genes: c.118C $>$ T, p.R40W; c.121C > T, p.R41W; c.127C > T, p.R43C; c.128G > A, p.R43H; c.268C > T, p.R90W; c.430delC, p.P145Lfs*42; c.587delC, p.P197Afs*22, and c.193G > C, p.D65H (NM_000554.5), respectively.

Five missense variants have been previously reported ${ }^{16,27-32,34,36}$. Three variants were reported in the heterozygous state: $\mathrm{p} . \mathrm{R} 40 \mathrm{~W}$ for CORD, p.R41W for CORD, and p.R43C for CORD. One variant was previously 


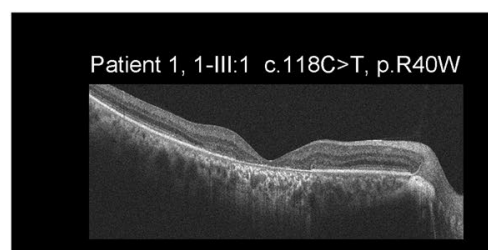

Patient 2, 1-II:3 c.118C>T, p.R40W

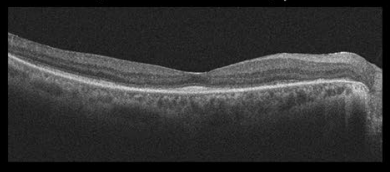

Patient 3, 2-Il:1 c. 118C>T, p.R40W

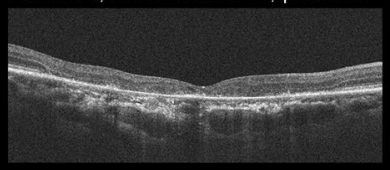

Patient 4, 2-I:2 c. 118C >T, p.R40W

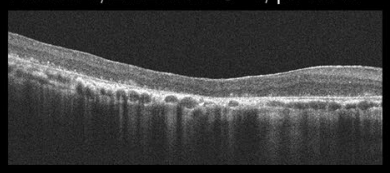

Patient 5, 3-II: 2 c. 118C>T, p.R40W

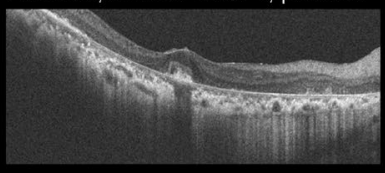

Patient 6, 6-III:2 c. 127C>T, p.R43C

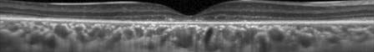

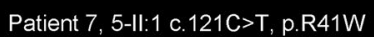

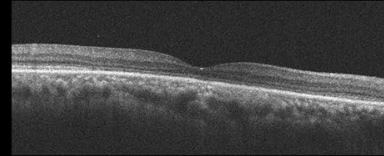

Patient 8, 5-I:1 c. 121C>T, p.R41W

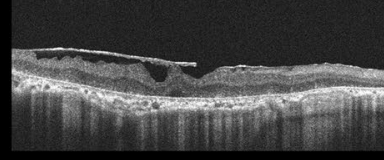

Patient 9, 6-III:1 c.127C>T, p.R43C

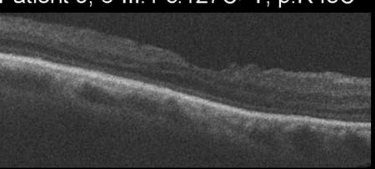

Patient 10, 6-III:2 c.127C>T, p.R43C

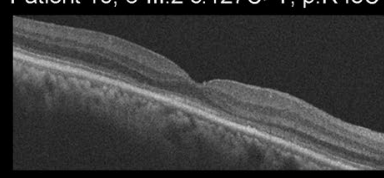

Patient 11, 7-III:3 c. 128G>A, p.R43H

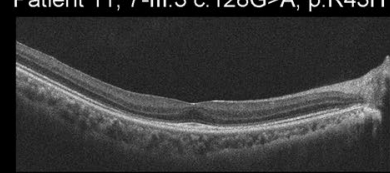

Patient 12, 7-II:2 c.128G>A, p.R43H

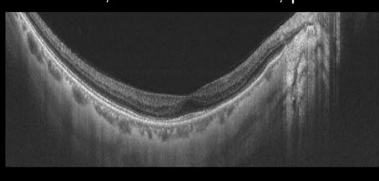

Patient 13, 8-II:2 c. 193G>C, p.D65H

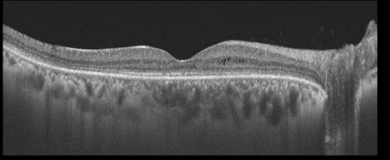

Patient 14, 9-Il:4 c.430delC, p.P145Lfs*42

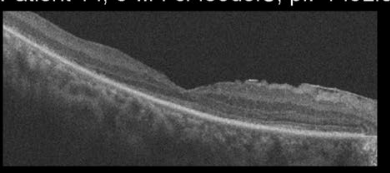

Patient $15,10-$ Il: 3 c. $268 \mathrm{C}>\mathrm{T}$, p.R90W

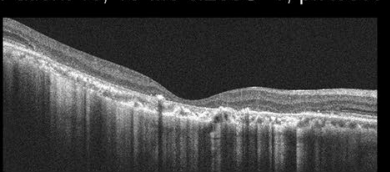

Patient $16,11-$ III: 3 c.430delC, p.P145Lfs*42

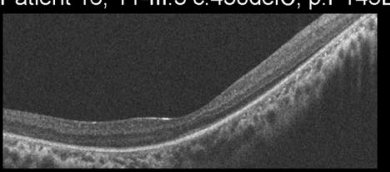

Patient 17, 12-IV:1 c.587delC, p.P197Afs*22

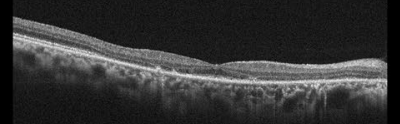

Patient 18, 13-III:1 c.587delC, p.P197Afs*22

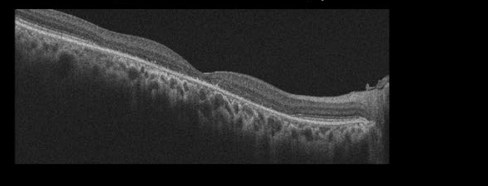

Figure 3. Spectral-domain optical coherence tomographic images from 18 patients with CRX-RD. Spectraldomain optical coherence tomographic images demonstrate outer retinal disruption at the macula in eight subjects (Patients 1, 3, 4-6, 8, 15, 18). Outer retinal disruption at the peri-macula is observed in 12 subjects (Patients 1-6, 8, 13-15, 17, 18). Intraretinal micro-cystic changes are noted in Patient 13. Epiretinal membrane is found in Patient 8. Marked preservation of the photoreceptor ellipsoid zone (EZ) line at the fovea is identified in eight subjects (Patients 2, 5, 7, 10-14), and slightly preserved EZ at the fovea isobserved in three subjects (Patients 9, 16, 17). Preserved foveal structure surrounded by parafoveal atrophy (i.e., bull's eye pattern) is found in six subjects (Patients $1,2,10,11,12,17$ ).

reported in homozygous and heterozygous states: p.R90W homozygous for LCA and heterozygous for CORD ${ }^{34,36}$. One variant was previously reported only in the homozygous state: p.D65H for $\mathrm{RP}^{29}$. Three variants have never been reported: p.R43H, p.P145Lfs*42, and p.P197Afs*22. Co-segregation analysis was performed for four variants with the samples of unaffected family members; p.R41W (heterozygous), p.R43H (heterozygous), p.D65H (homozygous), and p.P145Lfs*42 (heterozygous, de novo). Four variants were recurrent in our cohort: p.R40W (heterozygous), p.R41W (heterozygous), p.D65H (homozygous), and p.P197Afs*22 (heterozygous).

Together with the clinical features of the affected subjects and the model of inheritance in the pedigree, eight disease-causing variants in the CRX gene were determined.

In silico molecular genetic analysis. The detailed results of in silico molecular genetic analyses for the eight detected CRX variants are presented in Supplemental Tables 4 and 5. Schematic genetic and protein structures of CRX are shown in Fig. 4, and multiple alignment of seven species of CRX is presented in Supplemental Fig. 1.

Five missense variants were located within exon 3 (p.R40W, p.R41W, p.R43C, p.R43H, p.D65H) and the other missense variant (p.R90W) was in exon 4. Both exons are associated with the homeodomain of the CRX protein (residues 39-99; Fig. 4). Perfect evolutionary conservation was confirmed in five missense variants 


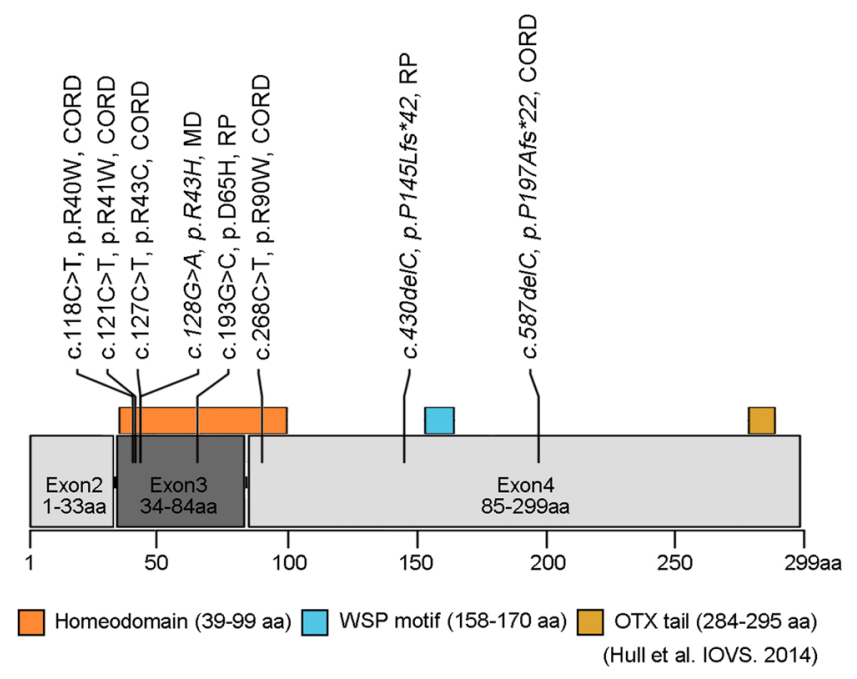

Figure 4. Schematic genetic and protein structures of CRX and the location of the detected variants. The CRX gene (ENST00000221996.7) contains four exons that encode a 299 amino acid protein containing a homeodomain, WSP motif, and OTX tail (Hull et al. 2014). Eight variants detected in this study are presented. Three novel variants are shown in Italics: p.R43H, p.P145Lfs*42, and p.P197Afs*22.

(p.R41W, p.R43C, p.R43H, p.D65H, p.R90W; Supplemental Fig. 1). Two truncating variants (p.P145Lfs*42 and p.P197Afs*22) were located in the last exon (exon 4), and nonsense-mediated decay did not appear to occur.

Allele frequency available for the five $C R X$ variants (p.R41W, p.R43C, p.R43H, p.D65H, and p.R90W) in the general population of East Asia/South Asia/Africa/Europe (non-Finnish) was $0.0058 \% / 0.0 \% / 0.0 \% / 0.00090 \%$, $0.0 \% / 0.0 \% / 0.0 \% / 0.0 \%, 0.0 \% / 0.0 \% / 0.0 \% / 0.00090 \%, 0.0058 \% / 0.0 \% / 0.0 \% / 0.0 \%, 0.0 \% / 0.0 \% / 0.0 \% / 0.013 \%$, respectively. Two variants had considerably higher allele frequencies in the East Asian population compared to the other populations (p.R41W and p.D65H).

General prediction, functional prediction, and conservation were assessed for the six missense variants and two single nucleotide deletion variants leading to frame shift and pathogenicity classification according to the American College of Medical Genetics and Genomics (ACMG) guidelines was performed. One pathogenic missense (p.R90W) and five likely pathogenic missense variants (p.R40W, p.R41W, p.R43C, p.R43H, and p.D65H) and the two likely pathogenic truncating variants (p.P145Lfs*42 and p.P197Afs*22) were revealed.

Overall, eight disease-causing variants in the CRX gene were identified in 13 families with ADCORD, ADRP, ADMD, and ARRP.

Genotype-phenotype association. Genotype subgroup classification was performed in the proband of 13 families (Patients 1, 3, 5, 6, 7, 10,11,13-18). There were eight subjects in genotype subgroup A (heterozygous missense), two in genotype subgroup B (homozygous missense), and three in genotype subgroup C (truncating variants). A distribution of the 13 families based on genotype subgroups and phenotype subgroups is shown in Table 2. There is a trend, but the number is not sufficient to statistically demonstrate a significant genotype-phenotype association.

\section{Discussion}

Detailed clinical and genetic characteristics of a Japanese cohort of 18 affected subjects from 13 families with $C R X-R D$ are illustrated. Diverse clinical presentations with different inheritance patterns were identified in $C R X-R D$, including nine families with molecularly confirmed ADCORD, one family with ADMD, two families with ARRP, and one family with ADRP.

To our knowledge, these are data from the largest cohort of CRX-RD and includes the highest number of ADCORD cases to date, despite there being a well-characterized study of CRX-RD in 11 families from the $\mathrm{UK}^{32}$. Six out of 30 families (20.0\%) diagnosed with CORD/MD/STGD and having a clear AD family history in the Japan Eye Genetics Consortium (JEGC) IRD cohort were associated with CRX-RD. The proportion of ADCRX-RD in molecularly confirmed ADCORD/MD/STGD in the JEGC cohort was considerably high (9/23 families, $39.1 \%$ ) in comparison with European cohorts (e.g., $15.6 \%$ in the UK cohort ${ }^{7}$. On the other hand, there were no families with LCA in our cohort, while four out of 11 families (36.4\%) with CRX-RD in the UK cohort manifested the severe LCA phenotype. There could be a bias in the enrolment of IRD patients, although ethnic variation can also occur in CRX-RD.

The median age of onset for $C R X-\mathrm{RD}$ was in the fifth decade in our cohort, although it varied from teenage years to the $8^{\text {th }}$ decade, which is considerably later than that of other CORD/MD/STGD patients (e.g., 19.0 years for $A B C A 4$-associated retinal disorder) ${ }^{37}$. In addition, over half of patients with late-onset disease ( $>45$ years) have preserved favourable VA, and two maintained VA even after 10 years of disease history (Patients 13 and 15). Fundus and FAF showed variable findings; however, the severity of macular atrophy was generally associated with the severity of VA decline, and a characteristic ring of increased AF signal was observed in most subjects $(>70 \%)$. Two-thirds of the subjects demonstrated preserved foveal structure often surrounded by parafoveal atrophy (i.e., 


\begin{tabular}{|l|l|l|l|l|}
\hline & $\begin{array}{l}\text { Genotype subgroup } \\
\text { A (heterozygous } \\
\text { missense) }\end{array}$ & $\begin{array}{l}\text { Genotype subgroup } \\
\text { B (homozygous } \\
\text { missense) }\end{array}$ & $\begin{array}{l}\text { Genotype subgroup } \\
\text { C (heterozygous } \\
\text { truncating) }\end{array}$ & Total \\
\hline Phenotype subgroup A (MD) & 1 & 0 & 0 & 1 \\
\hline Phenotype subgroup B (CORD) & 7 & 0 & 2 & 9 \\
\hline Phenotype subgroup C (RP) & 0 & 2 & 1 & 3 \\
\hline Total & 8 & 2 & 3 & 13 \\
\hline
\end{tabular}

Table 2. Associations between genotype subgroups and phenotype subgroups in 13 families with CRX-RD. Genotypic subgroup classification was performed based on the heterozygous/homozygous status of missense variants and presence of null variants (stop, frame shift, and splice site alteration): Genotype A-subjects with heterozygous missense variants; Genotype B-subjects with homozygous missense; and Genotype C-subjects with heterozygous truncating variants.

bull's eye pattern) with favourable VA, suggesting that late onset and morphological maintenance are indicators for preserved vision. These facts suggest that the severity and progression of visual impairment are mild in CRX-RD compared to that of CORD/MD/STGD caused by variants in other genes in the JEGC IRD cohort.

Electrophysiological findings of CRX-RD were also mildly affected in our cohort. Ten of 16 subjects (62.5\%) had no or mild dysfunction both in generalized rod and cone systems, all of whom were classified into MD or CORD. In contrast, two subjects with CORD showed moderate retinal dysfunction, one subject with CORD and three subjects with RP had severe retinal dysfunction. Interestingly, a lower b to a ratio in DA bright flash responses was identified in approximately half of the subjects. Although an interaction with the phototransduction cascade was suggested in a previous study of CRX- and OTX2-transfected iris-derived cells ${ }^{38}$, the molecular mechanism to support this phenomenon is unknown. This electronegative finding was also observed in the early stage of other CORD/MD/STGD and was not specific for CRX-RD ${ }^{13,39-41}$; however, this characteristic feature can be helpful to consider $C R X$-RD in patients with early maculopathy.

Phenotype subgroups were associated with disease severity in our cohort. The subjects with MD had later-onset disease, maintained VA, and normal generalized retinal function. In general, the subjects with CORD had late-onset disease but VA decline, and the subjects with RP presented early-onset disease, VA decline, and severe generalized retinal dysfunction. Thus, determining phenotype subgroups with comprehensive clinical assessments provides crucial information directly related to disease severity and progression.

Eight pathogenic/likely pathogenic $C R X$ variants were identified in our cohort, including three novel variants. One novel missense variant (p.R43H) located within the homeodomain of the CRX protein was found in two affected subjects with MD in a single family. A novel de novo truncating variant (p.P145Lfs*42) was revealed in a patient with early-onset RP. A novel recurrent truncating variant (p.P197Afs*22) was detected in two families with CORD. Comprehensive high-throughput gene screening of both affected and unaffected members was effective in obtaining a genetic diagnosis of $C R X-R D$ manifesting $A D$ or AR inheritance, as well as identifying de novo variants.

Four recurrent $C R X$ variants were identified in our cohort, and two of these with available allele frequency in the general population revealed considerably high frequency in East Asia (p.R41W and p.D65H). Several cases with ADCORD caused by the former variant (p.R41W) have been reported in East Asian ${ }^{16,28,35}$, and the phenotype was the same as that observed in our two families (Families 4 and 5). Jin et al. reported only one Japanese RP case homozygous for the latter variant (p.D65H), and the phenotype was the same as that observed in our two families (Families 8 and 9) ${ }^{29}$. Given these facts, these two $C R X$ variants with higher frequency are major causes of $C R X-R D$ in the East Asian population, leading to CORD and RP, respectively.

The patients with heterozygous missense variants located within the homeodomain frequently associated with CORD (7/8 families; $87.5 \%)$ are consistent with previous studies ${ }^{34}$. A postulated dominant-negative effect can be considered for these heterozygous missense variants within the homeodomain, as reported for p. K88 $\mathrm{N}^{42}$. Two families with homozygous missense variants (p.D65H) showed a severe phenotype, and the molecular mechanism is uncertain, unlike the well-studied homozygous missense variants (p.R90W), in which the mutant homeodomain showed a significantly reduced ability to transactivate the rhodopsin promoter and lower synergistic activation with the transcription factor $\mathrm{NRL}^{36}$. Three families with heterozygous truncating variants showed $\operatorname{CORD}(2 / 3,66 \%)$ or RP $(1 / 3,33 \%)$. Notably, nonsense-mediated decay could possibly modify the phenotype in such variants ${ }^{43}$.

There are limitations in this study. The selection bias related to the disease severity should be inherent, since it is unusual for genetically affected subjects with good vision to visit clinics/hospitals. In addition, this cross-sectional retrospective case series study does not include longitudinal information; thus, natural history studies in a larger cohort could provide more accurate information regarding the disease progression of $C R X$-RD. The molecular mechanisms of AD missense, AR missense, and AD truncating variants have not yet been clarified in $C R X-\mathrm{RD}$, and further functional investigation for each variant is required to conclude disease causation. The samples of affected and unaffected subjects of families with $C R X-R D$ are still small to conclude the molecularly confirmed inheritance and genotype-phenotype associations/correlations in such a diverse disorder; thus, larger cohort studies are required for further analyses.

In conclusion, this large nationwide cohort study delineates the clinical and genetic characteristics of $C R X-R D$ in Japan. A high proportion of ADCRX-RD was determined in Japan, which manifests late-onset ADCORD. The frequently found missense variants located within the homeodomain of the CRX protein can explain the mild phenotype of $C R X-R D$. In contrast, a relatively severe RP phenotype was associated with homozygous $C R X$ 
missense variants in a small number of patients. This information will help to monitor and counsel patients, as well as design future therapeutic trials.

\section{Methods}

The protocol of this study adhered to the tenets of the Declaration of Helsinki, which was approved by the ethics committee of the participating institutions from Japan: National Institute of Sensory Organs, National Hospital Organization Tokyo Medical Center (Reference; R18-029). Informed consent was received from all participants for the tests after an explanation of the procedures, and permission was obtained to use their medical data for research.

Participants. Participants with a clinical diagnosis of IRD and available genetic data were studied between 2008 and 2018 as a part of the Japan Eye Genetics Consortium Studies (JEGC studies; http://www.jegc.org/) ${ }^{44}$. A total of 1294 subjects from 730 families registered to the JEGC cohort were surveyed, including 30 families with ADCORD/MD/STGD (defined as families with clear autosomal dominant family history).

Clinical investigations. Medical history was obtained for all affected subjects and unaffected family members (where available). The onset of disease was defined as the age when any visual symptom was first noted by patients or parents or when the subject was first diagnosed.

Comprehensive ophthalmological examinations were performed in all affected subjects and unaffected family members (where available), including measurements of decimal VA converted to LogMAR units, ophthalmoscopy, fundus photography, FAF imaging, SD-OCT, kinetic and static visual field testing, and electrophysiological assessments according to the international standards of the International Society for Clinical Electrophysiology of Vision (ISCEV) ${ }^{45-48}$.

Phenotype subgroups. For the purpose of this study, phenotype subgroups were defined based on clinical manifestations such as onset of disease, natural course, lesioned part on retinal imaging, and pattern of retinal dysfunction, partially according to a previous report ${ }^{34}$ : LCA (including early-onset RP), a severe retinal dystrophy with early onset ( $<10$ years) and extinguished retinal function; RP (including rod-cone dystrophy), a progressive retinal dystrophy often initially presenting peripheral atrophy with generalized rod dysfunction greater than cone dysfunction; CORD, a progressive retinal dystrophy often initially presenting macular atrophy with generalized cone dysfunction greater than rod dysfunction; $\mathrm{MD}$, a progressive retinal dystrophy presenting macular atrophy with confined macular dysfunction despite no abnormalities in generalized cone and rod function.

Genetic screening of the $C R X$ gene. Genomic DNA was extracted from affected subjects and unaffected family members (where available for co-segregation analysis). Whole exome sequencing with target sequence analysis of 301 retinal disease-associated genes (based on RetNET; https://sph.uth.edu/retnet/home.htm; accessed on 1 July 2017) was performed according to a previously published method and through the Phenopolis platform (www.phenopolis.org) ${ }^{44,49}$. The identified variants were filtered on their allele frequency (less than 1\%) in the Human Genetic Variation Database (HGVD; http://www.genome.med.kyoto-u.ac.jp/SnpDB/about.htm; accessed on 1 July 2017), which provides allele frequency of the general Japanese population. Depth and coverage for the target areas were examined with the integrative Genomics Viewer (http://www.broadinstitute.org/igv/) to detect structural variants.

Disease-causing variants were determined from the called/detected variants in the 301 retinal disease-associated genes, in consideration of the clinical findings of the affected subjects, the model of inheritance in the pedigree, and the results of co-segregation analysis.

In silico molecular genetic analysis. The allele frequency of all detected $C R X$ variants in the HGVD, Integrative Japanese Genome Variation (iJGVD 2k; https://ijgvd.megabank.tohoku.ac.jp/; accessed on 1 August 2018), 1000 genome (http://www.internationalgenome.org/; accessed on 1 August 2018), and the genome Aggregation Database (gnomAD) (http://gnomad.broadinstitute.org/; accessed on 1 August 2018)was established.

All detected CRX variants were analysed with prediction programs: MutationTaster (http://www.mutationtaster.org/; accessed on 1 August 2018), FATHMM (http://fathmm.biocompute.org.uk/9; accessed on 1 August 2018), SIFT (https://www.sift.co.uk/; accessed on 1 August 2018), PROVEAN (http://provean.jcvi.org/index.php; accessed on 1 August 2018), and Polyphen 2 (http://genetics.bwh.harvard.edu/pph2/; accessed on 1 August 2018). Evolutionary conservation scores were calculated for all detected CRX variants via the UCSC database (https:// genome.ucsc.edu/index.html; accessed on 1 August 2018). Pathogenicity classification of all detected variants was performed based on the guidelines of the $\mathrm{ACMG}^{50}$.

Genotype subgroups. Genotypic subgroup classification was performed based on the heterozygous/ homozygous state of missense variants and presence of truncating variants: Genotype A-subjects with heterozygous missense variants; Genotype B-subjects with homozygous missense variants; and Genotype C-subjects with heterozygous truncating variants.

Received: 25 March 2019; Accepted: 6 May 2020;

Published online: 12 June 2020 


\section{References}

1. Liew, G., Michaelides, M. \& Bunce, C. A comparison of the causes of blindness certifications in England and Wales in working age adults (16-64 years), 1999-2000 with 2009-2010. BMJ Open. 4, e004015, https://doi.org/10.1136/bmjopen-2013-004015 (2014).

2. Aboshiha, J., Dubis, A. M., Carroll, J., Hardcastle, A. J. \& Michaelides, M. The cone dysfunction syndromes. Br. J. Ophthalmol. 100, 115-121, https://doi.org/10.1136/bjophthalmol-2014-306505 (2016).

3. Tee, J. J., Smith, A. J., Hardcastle, A. J. \& Michaelides, M. RPGR-associated retinopathy: clinical features, molecular genetics, animal models and therapeutic options. Br. J. Ophthalmol. 100, 1022-1027, https://doi.org/10.1136/bjophthalmol-2015-307698 (2016).

4. Tanna, P., Strauss, R. W., Fujinami, K. \& Michaelides, M. Stargardt disease: clinical features, molecular genetics, animal models and therapeutic options. Br. J. Ophthalmol. 101, 25-30, https://doi.org/10.1136/bjophthalmol-2016-308823 (2017).

5. Hirji, N., Aboshiha, J., Georgiou, M., Bainbridge, J. \& Michaelides, M. Achromatopsia: clinical features, molecular genetics, animal models and therapeutic options. Ophthalmic Genet. 39, 149-157, https://doi.org/10.1080/13816810.2017.1418389 (2018).

6. Kumaran, N. et al. In GeneReviews((R)) (eds M. P. Adam et al.) (2018).

7. Gill, J. S., Georgiou, M., Kalitzeos, A., Moore, A. T. \& Michaelides, M. Progressive cone and cone-rod dystrophies: clinical features, molecular genetics and prospects for therapy. Br J Ophthalmol, https://doi.org/10.1136/bjophthalmol-2018-313278 (2019).

8. Dias, M. F. et al. Molecular genetics and emerging therapies for retinitis pigmentosa: Basic research and clinical perspectives. Prog. Retin. Eye Res. 63, 107-131, https://doi.org/10.1016/j.preteyeres.2017.10.004 (2018).

9. Cremers, F. P., van den Hurk, J. A. \& den Hollander, A. I. Molecular genetics of Leber congenital amaurosis. Hum. Mol. Genet. 11, 1169-1176, https://doi.org/10.1093/hmg/11.10.1169 (2002).

10. Kondo, H. et al. Novel mutations in the RS1 gene in Japanese patients with X-linked congenital retinoschisis. Hum. Genome Var. 6, 3, https://doi.org/10.1038/s41439-018-0034-6 (2019).

11. Kominami, A. et al. Case of cone dystrophy with normal fundus appearance associated with biallelic POC1B variants. Ophthalmic Genet. 39, 255-262, https://doi.org/10.1080/13816810.2017.1408846 (2018).

12. Nakanishi, A. et al. Clinical and Genetic Findings of Autosomal Recessive Bestrophinopathy in Japanese Cohort. Am. J. Ophthalmol. 168, 86-94, https://doi.org/10.1016/j.ajo.2016.04.023 (2016).

13. Fujinami, K. et al. Clinical and molecular characteristics of childhood-onset Stargardt disease. Ophthalmology 122, 326-334, https:// doi.org/10.1016/j.ophtha.2014.08.012 (2015).

14. Fujinami, K. et al. Molecular characteristics of four Japanese cases with KCNV2 retinopathy: report of novel disease-causing variants. Mol. Vis. 19, 1580-1590 (2013).

15. Fujinami, K. et al. A longitudinal study of stargardt disease: clinical and electrophysiologic assessment, progression, and genotype correlations. Am. J. Ophthalmol. 155, 1075-1088 e1013, https://doi.org/10.1016/j.ajo.2013.01.018 (2013).

16. Oishi, M. et al. Next-generation sequencing-based comprehensive molecular analysis of 43 Japanese patients with cone and conerod dystrophies. Mol. Vis. 22, 150-160 (2016).

17. Oishi, M. et al. Comprehensive molecular diagnosis of a large cohort of Japanese retinitis pigmentosa and Usher syndrome patients by next-generation sequencing. Invest. Ophthalmol. Vis. Sci. 55, 7369-7375, https://doi.org/10.1167/iovs.14-15458 (2014).

18. Freund, C. L. et al. Cone-rod dystrophy due to mutations in a novel photoreceptor-specific homeobox gene (CRX) essential for maintenance of the photoreceptor. Cell 91, 543-553 (1997).

19. Chen, S. et al. Crx, a novel Otx-like paired-homeodomain protein, binds to and transactivates photoreceptor cell-specific genes. Neuron 19, 1017-1030 (1997).

20. Furukawa, T., Morrow, E. M. \& Cepko, C. L. Crx, a novel otx-like homeobox gene, shows photoreceptor-specific expression and regulates photoreceptor differentiation. Cell 91, 531-541 (1997).

21. Peng, G. H., Ahmad, O., Ahmad, F., Liu, J. \& Chen, S. The photoreceptor-specific nuclear receptor Nr2e 3 interacts with Crx and exerts opposing effects on the transcription of rod versus cone genes. Hum. Mol. Genet. 14, 747-764, https://doi.org/10.1093/hmg/ ddi070 (2005).

22. Kimura, A. et al. Both PCE-1/RX and OTX/CRX interactions are necessary for photoreceptor-specific gene expression. J. Biol. Chem. 275, 1152-1160(2000).

23. Evans, K. et al. Genetic linkage of cone-rod retinal dystrophy to chromosome $19 \mathrm{q}$ and evidence for segregation distortion. Nat. Genet. 6, 210-213, https://doi.org/10.1038/ng0294-210 (1994).

24. Freund, C. L. et al. De novo mutations in the CRX homeobox gene associated with Leber congenital amaurosis. Nat. Genet. 18, 311-312, https://doi.org/10.1038/ng0498-311 (1998).

25. Sohocki, M. M. et al. A range of clinical phenotypes associated with mutations in CRX, a photoreceptor transcription-factor gene. Am. J. Hum. Genet. 63, 1307-1315, https://doi.org/10.1086/302101 (1998).

26. Kitiratschky, V. B. et al. Cone and cone-rod dystrophy segregating in the same pedigree due to the same novel CRX gene mutation. Br. J. Ophthalmol. 92, 1086-1091, https://doi.org/10.1136/bjo.2007.133231 (2008).

27. Swain, P. K. et al. Mutations in the cone-rod homeobox gene are associated with the cone-rod dystrophy photoreceptor degeneration. Neuron 19, 1329-1336 (1997).

28. Itabashi, T. et al. Ocular findings in a Japanese family with an Arg41Trp mutation of the CRX gene. Graefes Arch. Clin. Exp. Ophthalmol. 241, 535-540, https://doi.org/10.1007/s00417-003-0704-y (2003).

29. Jin, Z. B. et al. Identifying pathogenic genetic background of simplex or multiplex retinitis pigmentosa patients: a large scale mutation screening study. J. Med. Genet. 45, 465-472, https://doi.org/10.1136/jmg.2007.056416 (2008).

30. Arai, Y. et al. Retinitis Pigmentosa with EYS Mutations Is the Most Prevalent Inherited Retinal Dystrophy in Japanese Populations. J. Ophthalmol. 2015, 819760, https://doi.org/10.1155/2015/819760 (2015).

31. Maeda, A. et al. Development of a molecular diagnostic test for Retinitis Pigmentosa in the Japanese population. Jpn. J. Ophthalmol. 62, 451-457, https://doi.org/10.1007/s10384-018-0601-x (2018).

32. Huang, L. et al. Molecular genetics of cone-rod dystrophy in Chinese patients: New data from 61 probands and mutation overview of 163 probands. Exp. Eye Res. 146, 252-258, https://doi.org/10.1016/j.exer.2016.03.015 (2016).

33. Ibrahim, M. T. et al. A complete, homozygous CRX deletion causing nullizygosity is a new genetic mechanism for Leber congenital amaurosis. Sci. Rep. 8, 5034, https://doi.org/10.1038/s41598-018-22704-z (2018).

34. Hull, S. et al. The phenotypic variability of retinal dystrophies associated with mutations in CRX, with report of a novel macular dystrophy phenotype. Invest. Ophthalmol. Vis. Sci. 55, 6934-6944, https://doi.org/10.1167/iovs.14-14715 (2014).

35. Zhang, Q. et al. Screening for CRX gene mutations in Chinese patients with Leber congenital amaurosis and mutational phenotype. Ophthalmic Genet. 22, 89-96 (2001).

36. Swaroop, A. et al. Leber congenital amaurosis caused by a homozygous mutation (R90W) in the homeodomain of the retinal transcription factor CRX: direct evidence for the involvement of CRX in the development of photoreceptor function. Hum. Mol. Genet. 8, 299-305 (1999).

37. Fujinami, K. et al. Detailed genetic characteristics of an international large cohort of patients with Stargardt disease: ProgStar study report 8. Br. J. Ophthalmol. 103, 390-397, https://doi.org/10.1136/bjophthalmol-2018-312064 (2019).

38. Akagi, T. et al. Otx2 homeobox gene induces photoreceptor-specific phenotypes in cells derived from adult iris and ciliary tissue. Invest. Ophthalmol. Vis. Sci. 45, 4570-4575, https://doi.org/10.1167/iovs.04-0697 (2004).

39. Michaelides, M., Hardcastle, A. J., Hunt, D. M. \& Moore, A. T. Progressive cone and cone-rod dystrophies: phenotypes and underlying molecular genetic basis. Surv. Ophthalmol. 51, 232-258, https://doi.org/10.1016/j.survophthal.2006.02.007 (2006). 
40. Fujinami, K. et al. The clinical effect of homozygous ABCA4 alleles in 18 patients. Ophthalmology 120, 2324-2331, https://doi. org/10.1016/j.ophtha.2013.04.016 (2013).

41. Khan, K. N. et al. Early Patterns of Macular Degeneration in ABCA4-Associated Retinopathy. Ophthalmology 125, 735-746, https:// doi.org/10.1016/j.ophtha.2017.11.020 (2018).

42. Nichols, L. L. 2nd et al. Two novel CRX mutant proteins causing autosomal dominant Leber congenital amaurosis interact differently with NRL. Hum. Mutat. 31, E1472-1483, https://doi.org/10.1002/humu.21268 (2010).

43. Lejeune, F. \& Maquat, L. E. Mechanistic links between nonsense-mediated mRNA decay and pre-mRNA splicing in mammalian cells. Curr. Opin. Cell Biol. 17, 309-315, https://doi.org/10.1016/j.ceb.2005.03.002 (2005).

44. Fujinami, K. et al. Novel RP1L1 Variants and Genotype-Photoreceptor Microstructural Phenotype Associations in Cohort of Japanese Patients With Occult Macular Dystrophy. Invest. Ophthalmol. Vis. Sci. 57, 4837-4846, https://doi.org/10.1167/iovs.1619670 (2016).

45. Hood, D. C. et al. ISCEV standard for clinical multifocal electroretinography (mfERG) (2011 edition). Doc. Ophthalmol. 124, 1-13, https://doi.org/10.1007/s10633-011-9296-8 (2012).

46. McCulloch, D. L. et al. Erratum to: ISCEV Standard for full-field clinical electroretinography (2015 update). Doc. Ophthalmol. 131, 81-83, https://doi.org/10.1007/s10633-015-9504-z (2015).

47. McCulloch, D. L. et al. ISCEV Standard for full-field clinical electroretinography (2015 update). Doc. Ophthalmol. 130, 1-12, https:// doi.org/10.1007/s10633-014-9473-7 (2015).

48. Robson, A. G. et al. ISCEV guide to visual electrodiagnostic procedures. Doc. Ophthalmol. 136, 1-26, https://doi.org/10.1007/ s10633-017-9621-y (2018).

49. Pontikos, N. et al. Phenopolis: an open platform for harmonization and analysis of genetic and phenotypic data. Bioinformatics 33, 2421-2423, https://doi.org/10.1093/bioinformatics/btx147 (2017).

50. Richards, S. et al. Standards and guidelines for the interpretation of sequence variants: a joint consensus recommendation of the American College of Medical Genetics and Genomics and the Association for Molecular Pathology. Genet. Med. 17, 405-424, https://doi.org/10.1038/gim.2015.30 (2015).

\section{Acknowledgements}

Yu Fujinami-Yokokawa is supported by grants from Grant-in-Aid for Young Scientists of the Ministry of Education, Culture, Sports, Science and Technology, Japan (18K16943). Kaoru Fujinami is supported by grants from Grant-in-Aid for Young Scientists (A) of the Ministry of Education, Culture, Sports, Science and Technology, Japan (16H06269), grants from Grant-in-Aid for Scientists to support international collaborative studies of the Ministry of Education, Culture, Sports, Science and Technology, Japan (16KK01930002), grants from National Hospital Organization Network Research Fund (H30-NHO-Sensory Organs-03), grants from FOUNDATION FIGHTING BLINDNESS ALAN LATIES CAREER DEVELOPMENT PROGRAM (CF-CL-0416-0696-UCL), grants from Health Labour Sciences Research Grant, The Ministry of Health Labour and Welfare (201711107A), grants from Japanese agency of medical research and development (AMED; 18ek0109355h0001), and grants from Great Britain Sasakawa Foundation Butterfield Awards. Gavin Arno is supported by a Fight for Sight (UK) Early career investigator award, NIHR-BRC at Moorfields Eye Hospital and the UCL Institute of Ophthalmology, NIHR-BRC at Great Ormond Street Hospital and UCL Institute of Child Health, and Great Britain Sasakawa Foundation Butterfield Award, UK. Nikolas Pontikos is funded by the NIHR-BRC at Moorfields Eye Hospital and the UCL Institute of Ophthalmology. Toshihide Kurihara is supported by Tsubota Laboratory, Inc, Fuji Xerox Co., Ltd, Kirin Company, Ltd, Kowa Company, Ltd, Novartis Pharmaceuticals, Santen Pharmaceutical Co. Ltd, and ROHTO Pharmaceutical Co.,Ltd. Takeshi Iwata is supported by AMED (18ek0109282h0002). Kazushige Tsunoda is supported by AMED, the Ministry of Health, Labor and Welfare, Japan (18ek0109282h0002), Grantsin-Aid for Scientific Research, Japan Society for the Promotion of Science, Japan (H26-26462674), grants from National Hospital Organization Network Research Fund, Japan (H30-NHO-Sensory Organs-03) and Novartis Research Grant (2018). Role of the Funder/Sponsor: The funding sources had no role in the design and conduct of the study; collection, management, analysis, and interpretation of the data; preparation, review, or approval of the manuscript; and decision to submit the manuscript for publication.

\section{Author contributions}

Each author meets the ICMJE criteria for authorship and agrees with all contents of the manuscript. Yu FujinamiYokokawa and Kaoru Fujinami. Equal contributions and regarded as joint first authors. Y.F., K.F., G.A., N.P., L.Y., X.L., T.I. and K.T. designed the research. Y.F., K.F., K.K., T.H., S.U., A.M., K.S., G.A., N.P., L.Y., X.L., H.S., S.K., K.M., T.K., H.T., N.N., S.K., K.Y., Y.M., T.K., K.T., H.M., T.I. and K.T. performed data acquisition and/or research execution. All authors analyzed and/or interpret data. Y.F., K.F., G.A., N.P., L.Y., X.L., T.I. and K.T. prepared the manuscript. All authors reviewed the manuscript. K.F. (corresponding author) has full access to all the data in the present study and takes responsibility for the integrity of the data and the accuracy of the data analysis.

\section{Competing interests}

All authors have completed and submitted the ICMJE Form for Disclosure of Potential Conflicts of Interest. Individual investigators who participate in the sponsored project(s) are not directly compensated by the sponsor but may receive salary or other support from the institution to support their effort on the project(s). Kaoru Fujinami is a paid consultant of Astellas Pharma Inc, Kubota Pharmaceutical Holdings Co., Ltd, and Acucela Inc., Novartis AG., Janssen Pharmaceutica, Sanofi Genzyme, NightstaRx Limited. Kaoru Fujinami reports personal fees from Astellas Pharma Inc, personal fees from Kubota Pharmaceutical Holdings Co., Ltd., personal fees from Acucela Inc., personal fees from NightStar., personal fees from SANTEN Company Limited, personal fees from Foundation Fighting Blindness, personal fees from Foundation Fighting Blindness Clinical Research Institute, personal fees from Japanese Ophthalmology Society, personal fees from Japan Retinitis Pigmentosa Society. Laboratory of Visual Physiology, Division of Vision Research, National Institute of Sensory Organs, National Hospital Organization, Tokyo Medical Center, Tokyo, Japan is supported by grants from Astellas Pharma Inc (NCT03281005), outside the submitted work. Toshihide Kurihara is supported by Tsubota 
Laboratory, Inc, Fuji Xerox Co., Ltd, Kirin Company, Ltd, Kowa Company, Ltd, Novartis Pharmaceuticals, Santen Pharmaceutical Co. Ltd, and ROHTO Pharmaceutical Co.,Ltd, outside the submitted work.

\section{Additional information}

Supplementary information is available for this paper at https://doi.org/10.1038/s41598-020-65737-z.

Correspondence and requests for materials should be addressed to K.F.

Reprints and permissions information is available at www.nature.com/reprints.

Publisher's note Springer Nature remains neutral with regard to jurisdictional claims in published maps and institutional affiliations.

Open Access This article is licensed under a Creative Commons Attribution 4.0 International License, which permits use, sharing, adaptation, distribution and reproduction in any medium or format, as long as you give appropriate credit to the original author(s) and the source, provide a link to the Creative Commons license, and indicate if changes were made. The images or other third party material in this article are included in the article's Creative Commons license, unless indicated otherwise in a credit line to the material. If material is not included in the article's Creative Commons license and your intended use is not permitted by statutory regulation or exceeds the permitted use, you will need to obtain permission directly from the copyright holder. To view a copy of this license, visit http://creativecommons.org/licenses/by/4.0/.

(c) The Author(s) 2020

\section{Japan Eye Genetics Consortium}

Toshihide Nishimura ${ }^{20}$, Yoshihide Hayashizaki ${ }^{21}$, Mineo Kondo ${ }^{22}$, Nobuhiro Shimozawa ${ }^{23}$, Masayuki Horiguchi ${ }^{24}$, ShuichiYamamoto ${ }^{25}$, Manami Kuze ${ }^{26}$, Nobuhisa Naoi ${ }^{27}$, Shigeki Machida ${ }^{28}$, Yoshiaki Shimada ${ }^{29}$, Makoto Nakamura ${ }^{30}$, Takashi Fujikado ${ }^{31}$, Yoshihiro Hotta ${ }^{32}$, Masayo Takahashi ${ }^{33}$, Kiyofumi Mochizuki ${ }^{34}$, Akira Murakami ${ }^{35}$, Hiroyuki Kondo ${ }^{36}$, Susumu Ishida ${ }^{37}$, Mitsuru Nakazawa ${ }^{38}$, Tetsuhisa Hatase ${ }^{39}$, Tatsuo Matsunaga ${ }^{40}$, Akiko Maeda ${ }^{33}$, Kosuke Noda ${ }^{37}$, Atsuhiro Tanikawa ${ }^{24}$, Syuji Yamamoto ${ }^{41}$, Hiroyuki Yamamoto ${ }^{41}$, Makoto Araie $^{42}$, Makoto Aihara ${ }^{43}$, Toru Nakazawa ${ }^{44}$, Tetuju Sekiryu ${ }^{45}$, Kenji Kashiwagi ${ }^{46}$, Kenjiro Kosaki ${ }^{47}$, Carninci Piero ${ }^{48}$, Takeo Fukuchi ${ }^{49}$, Atsushi Hayashi ${ }^{50}$, Katsuhiro Hosono ${ }^{32}$, Keisuke Mori $^{51}$, Kouji Tanaka ${ }^{52}$, Koichi Furuya ${ }^{52}$, Keiichirou Suzuki ${ }^{53}$, Ryo Kohata ${ }^{43}$, Yasuo Yanagi ${ }^{54}$, Yuriko Minegishi, Daisuke lejima, Akiko Suga, Brian P. Rossmiller, Yang Pan, Tomoko Oshima, Mao Nakayama, Yu Teruyama, Megumi Yamamoto, Naoko Minematsu, Hideko Sanbe, Daisuke Mori ${ }^{55}$, Yusuke Kijima ${ }^{55}$, Go Mawatari ${ }^{27}$, Kentaro Kurata ${ }^{32}$, Norihiro Yamada ${ }^{11}$, Masayosi Itoh ${ }^{21}$, Hideya Kawaji ${ }^{21}$ \& Yasuhiro Murakawa ${ }^{56}$

${ }^{20}$ Department of Translational Medicine Informatics, St. Marianna University School of Medicine, Kawasaki, 216 8511, Japan. ${ }^{21}$ RIKEN Preventive Medicine and Diagnosis Innovation Program, Wako, 351-0198, Japan. ${ }^{22}$ Department of Ophthalmology, Mie University Graduate School of Medicine, Mie, 514-8507, Japan. ${ }^{23}$ National Institutes of Biomedical Innovation, Health and Nutrition, Tsukuba, 305-0843, Japan. ${ }^{24}$ Department of Ophthalmology, Fujita Health University School of Medicine, Toyoake, 470-1192, Japan. ${ }^{25}$ Department of Ophthalmology and Visual Science, Chiba University Graduate School of Medicine, Chiba, 263-8522, Japan. ${ }^{26}$ Department of Ophthalmology, Matsusaka Central General Hospital, Matsusaka, 515-8566, Japan. ${ }^{27}$ Department of Ophthalmology, University of Miyazaki, Miyazaki, 889-2192, Japan. ${ }^{28}$ Saitama Medical Center, Dokkyo Medical University, Koshigaya, Saitama, 345-8555, Japan. ${ }^{29}$ Fujita Health Univ Banbuntane Hosp, Nagoya, 454-8509, Japan. ${ }^{30}$ Department of Ophthalmology, Kobe University Hospital, Kobe, 650-0017, Japan. ${ }^{31}$ Osaka Univ Medical School, Suita, 565-0871, Japan. ${ }^{32}$ Hamamatsu University School of Medicine, Hamamatsu, Japan. ${ }^{33}$ Riken Center for Developmental Biology, Kobe, 650-0047, Japan. ${ }^{34}$ Department of Ophthalmology Gifu University Graduate School of Medicine, Gifu, 5011112, Japan. ${ }^{35}$ Department of Ophthalmology, Juntendo University Faculty of Medicine, Tokyo, 113-8431, Japan. ${ }^{36}$ Department of Ophthalmology, University of Occupational and Environmental Health, Kitakyuusyuu, 807-8556, Japan. ${ }^{37}$ Laboratory of Ocular Cell Biology and Visual Science, Department of Ophthalmology, Faculty of Medicine and Graduate School of Medicine, Hokkaido University, Sapporo, Hokkaido, 060-0808, Japan. ${ }^{38}$ Hirosaki University Graduate School of Medicine, Hirosaki, 036-8562, Japan. ${ }^{39}$ Graduate School of Medical and Dental Sciences, Niigata University, Niigata, 951-8510, Japan. ${ }^{40}$ Division of Hearing and Balance Research, National Institute of Sensory Organs, National Hospital Organization, Tokyo Medical Center, Tokyo, 158-8531, Japan. ${ }^{41}$ Hitoshi Ophthalmology Clinic, Nishinomiya, 663-8184, Japan. ${ }^{42}$ Kanto Central Hospital of the Mutual Aid Association of Public School Teachers, Tokyo, 158-8531, Japan. ${ }^{43}$ Department of Ophthalmology, The University of Tokyo, Tokyo, 113-8654, Japan. ${ }^{44}$ Department of ophthalmology, Graduate School of Medicine, Tohoku University, Sendai, 980-8577, Japan. ${ }^{45}$ Department of Ophthalmology, Fukushima Medical University School of Medicine, Fukushima, 960-1247, Japan. ${ }^{46}$ Department of Ophthalmology, University of Yamanashi, Chuo, 409-3898, Japan. ${ }^{47}$ Center for Medical Genetics, Keio University School of Medicine, Tokyo, 160-8582, Japan. ${ }^{48}$ Division of Genomic Technologies, Laboratory for Transcriptome Technology, RIKEN Center for Integrative Medical Sciences, Yokohama, 230-0045, Japan. ${ }^{49}$ Division of Ophthalmology and Visual Science, Graduate School of Medical and Dental Sciences, Niigata University, Niigata, 950-2181, Japan. ${ }^{50}$ Department of Radiological Sciences, Graduate School of Medicine and Pharmaceutical Sciences, 
University of Toyama, Toyama, 930-0194, Japan. ${ }^{51}$ Department of Ophthalmology, International University of Health and Welfare, Nasu-shiobara, 329-2763, Japan. ${ }^{52}$ Department of Ophthalmology, Nihon University Hospital, Tokyo, 101-8309, Japan. ${ }^{53}$ Institute for Advanced Co-Creation Studies, Osaka University, Suita, 565-0871, Japan. ${ }^{54}$ Department of Ophthalmology, Asahikawa Medical University, Asahikawa, 078-8802, Japan. ${ }^{55}$ Graduate School of Agricultural and Life Sciences, The University of Tokyo, Tokyo, 113-8654, Japan. ${ }^{56}$ RIKEN Preventive Medicine and Diagnosis Innovation Program, Yokohama, 230-0045, Japan. 